\title{
Confirmation of Nuclear Heating Rate for Installation of Cold Neutron Source at HANARO
}

\author{
Myong-Seop Kim* and Byung-Gun Park \\ Korea Atomic Energy Research Institute \\ *mskim@kaeri.re.kr
}

\begin{abstract}
In order to determine the capacity of the cold neutron source refrigerator of HANARO, the nuclear heating rate at $\mathrm{CN}$ vertical hole is measured by using the heat-flow calorimetric method and confirmed by the calculation. The heating rate measurement device of HANARO was composed of a calorimeter sensor, an air containing aluminum sleeve for fitting the sensor to the $\mathrm{CN}$ hole, aluminum weight and a lead wire assembly. The calorimeter sensor consists of a cylindrical Al sample and container, two thermocouples and the electric heater for the calibration of the calorimeter. The sample is separated by an air gap from the Al container surrounded by an air containing Al sleeve. After installation of the calorimeter at a measurement position of HANARO, the heat transfer inside the calorimeter was simulated by the electric heating for the sample. The nuclear heating rates at the $C N$ hole were determined at three reactor powers of 1,4 and $8 \mathrm{MW}$ by using the calibration curve and the temperature measurements at each reactor power. The measured nuclear heating rate per unit mass of Al sample at $8 \mathrm{MW}$ reactor power is $0.143 \mathrm{~W} / \mathrm{g}$ and it is equivalent to the $0.494 \mathrm{~W} / \mathrm{g}$ at $30 \mathrm{MW}$. The nuclear heating rate was calculated by using the MCNP code. The calculation model for the whole facility including the reactor core and the reflector tank were established. In the calculation procedure, the heat generations by various radiations were evaluated with considering the prompt, delayed and activation effects. The measured heating rate was reasonably well supported by the calculation using the cold neutron facility design code. It will be very useful for the moderator cell of cold neutron source of HANARO.
\end{abstract}

Keywords-calculation of heat generation in research reactor, calorimeter, cold neutron source refrigerator, HANARO, nuclear heating rate

\section{INTRODUCTION}

$\mathrm{T}$ $\mathrm{HE}$ heat removal capacity of the moderator cell is essential information for a cold neutron source (CNS) design in a research reactor. In order to determine the capacity of the refrigerator, the nuclear heating rate at the CNS position should be confirmed. The nuclear heating in a research reactor arises from the nuclear fissions and the interactions with gamma-rays, fast and thermal neutrons. The heating rate can be determined by several methods such as the calorimetry, the ionization chambers and the chemical dosimeters [1].

Calorimetric dosimeters have various advantages for highdose applications. The operation of the calorimeter is possible

M. S. Kim is with the Korea Atomic Energy Research Institute, Daedeokdaero 989-111, Yuseong, Daejeon, 34057, Korea (e-mail: mskim@kaeri.re.kr) by measuring the total amount of energy that is deposited as heat in an isolated mass. The measurement of the temperature rise in a calorimetric dosimeter provides a direct measurement of the full energy imparted to matter by radiation. The thermocouples and the thermistors are sufficiently sensitive and small enough to measure the temperature change with sufficient accuracy and precision [2].

In this work, we measured the nuclear heating rate at the $\mathrm{CN}$ hole of HANARO, a $30 \mathrm{MW}$ research reactor, by using the calorimetric method in order to install the cold neutron source. Also, the nuclear heating rate was calculated and compared with the measurements. In the calculation procedure, the heat generation rate caused by the various heat sources such as fission products, neutrons and gamma-rays were considered. Furthermore, the effect of the decay radiations from the activated structural materials in the reactor core and reflector was estimated. It will be very useful for the moderator cell design of the cold neutron source of HANARO.

\section{CONCEPT OF CALORIMETER OPERATION}

The adiabatic calorimeter must be loaded during the reactor power operation with maintaining the vacuum $[3,4]$, and only instantaneous measurements at a low reactor power are possible. Therefore, the concept of a heat flow calorimeter was introduced to measure the heating rate of the $\mathrm{CN}$ hole of HANARO instead of the adiabatic calorimeter.

Assuming a good thermal conductivity of the sample and the small heat transfer coefficient, the power integrated over the volume of the sample at a position of the research reactor in equilibrium condition of steady state,

$P=h s\left(T_{s}-T_{e}\right)$

where, $T_{s}, T_{e}:$ sample and container temperatures,

$$
\begin{aligned}
h & : \text { heat transfer coefficient, } \\
s & : \text { sample surface area, } \\
1 / h s & : \text { thermal resistance. }
\end{aligned}
$$

From the above equation, if the surface temperature is uniform, and if the thermal resistance is known, the power can be obtained by measuring the equilibrium temperature

B. G. Park is with the Korea Atomic Energy Research Institute, Daedeokdaero 989-111, Yuseong, Daejeon, 34057, Korea (e-mail: bgpark@kaeri.re.kr). 
difference [3]. It is necessary to know the thermal resistance in order to obtain the heating rate, and it may be determined by the calculation. But, it is preferable to simulate the dose rate by the thermal heating produced in the sample by the Joule effect [5].

\section{EXPERIMENTAL SETUP}

The heating rate measurement facility at the $\mathrm{CN}$ hole of HANARO was designed and composed of a calorimeter sensor, an air containing aluminum sleeve for fitting the sensor to the $\mathrm{CN}$ hole, aluminum weight and a lead wire assembly as shown in Fig. 1.
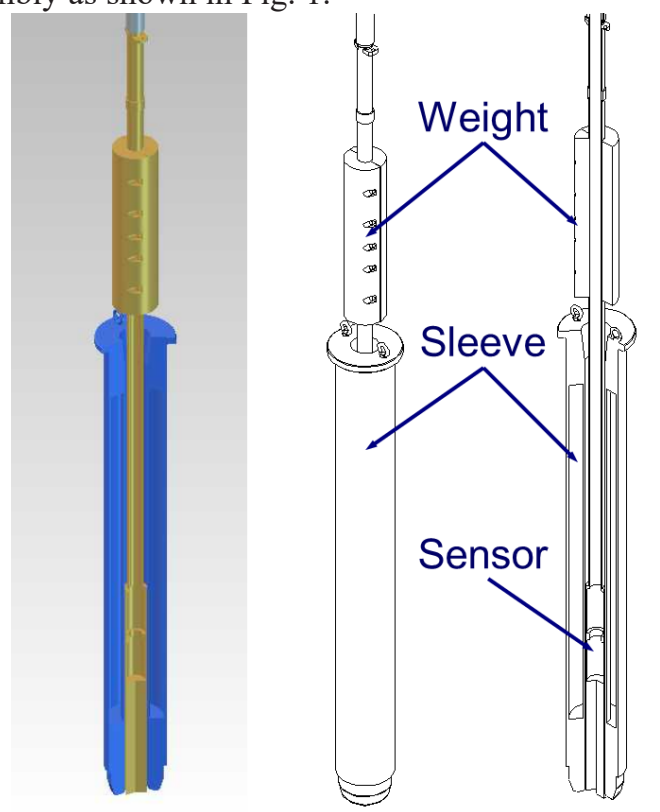

Fig. 1. The heating rate measurement facility at the $\mathrm{CN}$ hole of HANARO.

Fig. 2 shows the detailed layout of the sensor part of the calorimeter. The calorimeter sensor consists of a cylindrical aluminum (Al) sample, Al container, two thermocouples and the electric heater for a calibration. The sample is separated by an air gap from the $\mathrm{Al}$ container surrounded by an air containing Al sleeve. The longitudinal center of Al sample is equal to the center of reactor core. The calibration heater allows one to determine the thermal resistivity in eq. (1), and this calibration gives a simulation of the heat transfer of the calorimeter over the temperature range and under the irradiation condition. Table. 1 shows the detailed specification of the sample.

TABLE 1

DetAiled SPECIFICATION OF THE SENSOR.

\begin{tabular}{|l|l|}
\hline \multicolumn{1}{|c|}{ Parameters } & \multicolumn{1}{c|}{ Figures } \\
\hline Outer diameter of the sensor & $56 \mathrm{~mm}$ \\
Al sample & \\
Diameter & $19.3 \mathrm{~mm}$ \\
Length & $49.9 \mathrm{~mm}$ \\
Weight & $39.345 \mathrm{~g}$ \\
Material & Al6061 \\
\hline
\end{tabular}

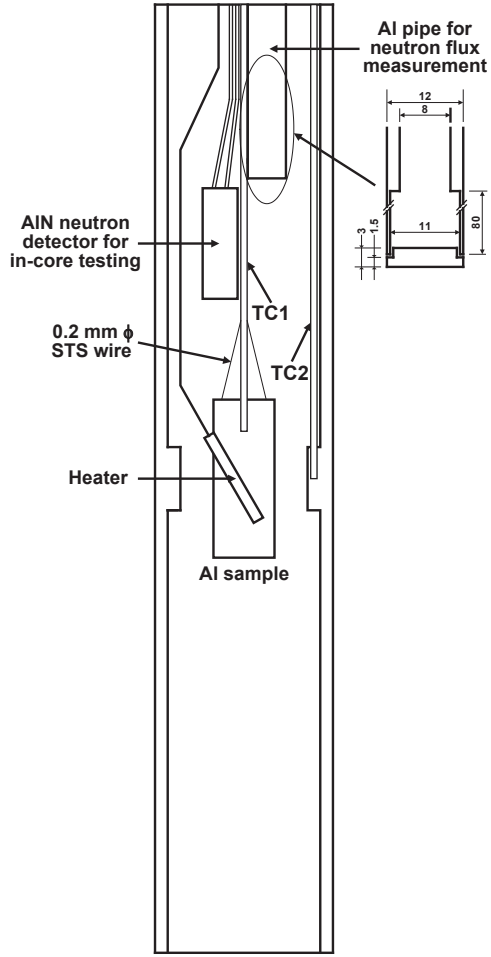

Fig. 2. Detailed layout of the sensor part of calorimeter.

\section{CALIBRATION EXPERIMENT}

Fabricated facility for the heating rate measurement was installed at the $\mathrm{CN}$ hole of HANARO, and the calibration experiments were performed. The temperatures of the sample and container were measured with a variation of the electric power supplied to the heater loaded in the sample. The maximum temperature of the aluminum sample was $385^{\circ} \mathrm{C}$ at the electric power of $20 \mathrm{~W}$. The temperature change of the container was several ${ }^{\circ} \mathrm{C}$ in the whole power range.

Fig. 3 shows the whole trends of the temperature changes of the $\mathrm{Al}$ sample and the container in the calibration experiment for the high electric power range.

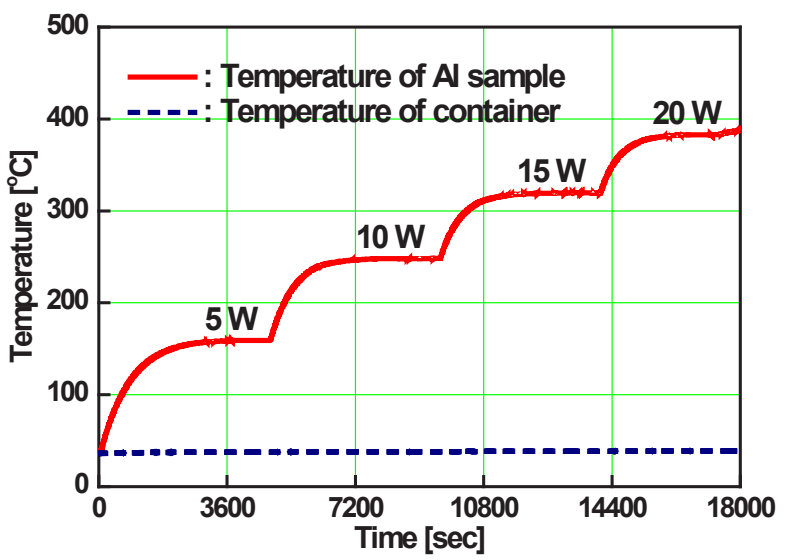

Fig. 3. Whole trends of the temperature changes of the Al sample and the container in the calibration experiment for the high electric power range. 


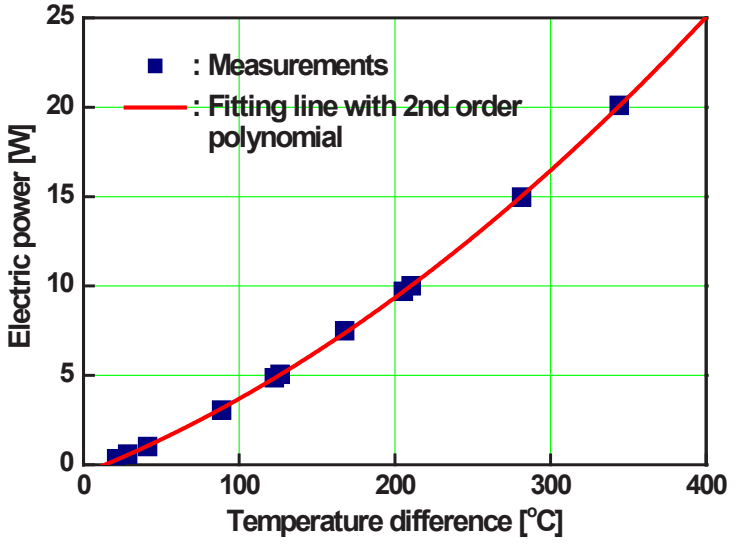

Fig. 4. Result of the calibration experiment.

From this calibration experiment, the relationship between the power supplied to the heater and the temperature difference was determined, and Fig. 4 represents the result of the calibration experiment. In the figure, the solid line is fitting to the measurements with 2 nd order polynomial. The calibration curve is not linear because the convective and radiative heat transfers are increased in high sample temperature range [6].

\section{Calculation}

The nuclear heating rate at $\mathrm{CN}$ vertical hole of HANARO was calculated by using the MCNP6.1 code. The calculation model for the whole facility including the reactor core and the reflector tank were established for the reactor operation of 32$2^{\text {nd }}$ beginning-of-cycle of HANARO.

The material composition and source distribution of depleted-core was determined using HANAFMS, HANARO core management program. HANAFMS is based on the WIMS for the lattice calculation and VENTURE for the core calculation. Fig. 5 shows the calculation model for the $32-2^{\text {nd }}$ period of the HANARO operation.
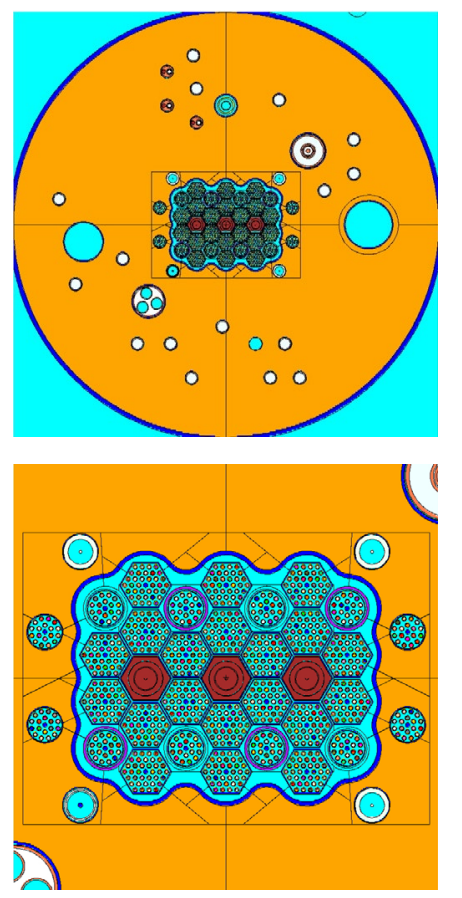

Fig. 5. The reactor model for the calculation of the nuclear heating rate at the $\mathrm{CN}$ hole.
The neutron and gamma-ray transport were simulated in almost all materials of the MCNP model including nuclear fuel, heavy water and heavy water tank, reactor flow tube, inner shell, heating rate measurement facility, etc. And each contribution to the nuclear heating of $\mathrm{Al}$ sample inside the sensor was evaluated, respectively. The control rod position in the calculation was set on the same as experiment.

The radiation contributions to the nuclear heating rate of the sample through the materials of the nuclear fuel and the structure of the experimental setup are as follow.

- Fission fragments

- Fission neutrons and gamma-rays

- Capture gamma-rays by neutron absorptions

- Beta and gamma-rays from decay of fission fragments

- Beta and gamma-rays from activations of structural materials

- Beta and gamma-rays from activation of aluminum sample

The ACT1 nuclear data library was used for calculation of delayed gamma-rays from $\mathrm{Al}^{27}(\mathrm{n}, \gamma) \mathrm{Al}^{28}$ reaction in aluminum sample. Contribution of delayed gamma-rays from fission fragment in the fuel was deduced from the delayed gammaray flux value calculated at the $\mathrm{CN}$ hole.

\section{RESULTS}

The nuclear heating rates at the $\mathrm{CN}$ hole were determined at three reactor powers of 1,4 and $8 \mathrm{MW}$ by using the calibration curve and the temperature measurements at each reactor power. The measured nuclear heating rate per unit mass of $\mathrm{Al}$ sample at $8 \mathrm{MW}$ reactor power is $0.143 \mathrm{~W} / \mathrm{g}$ as shown in the TABLE 2 and Fig. 6.

TABLE 2

\begin{tabular}{|c|c|c|c|c|c|}
\hline $\begin{array}{c}\text { Reactor } \\
\text { power } \\
{[\mathrm{MW}]}\end{array}$ & $\begin{array}{c}\text { Container } \\
\text { temperature } \\
{\left[{ }^{\circ} \mathrm{C}\right]}\end{array}$ & $\begin{array}{c}\text { Sample } \\
\text { temperature } \\
{\left[{ }^{\circ} \mathrm{C}\right]}\end{array}$ & $\begin{array}{c}\text { Temperature } \\
\text { difference } \\
{\left[{ }^{\circ} \mathrm{C}\right]}\end{array}$ & $\begin{array}{c}\text { Nuclear } \\
\text { heating } \\
\text { rate at } \\
\text { sample } \\
{[\mathrm{W}]}\end{array}$ & $\begin{array}{c}\text { Heating rate } \\
\text { per sample } \\
\text { unit mass } \\
{[\mathrm{W} / \mathrm{g}]}\end{array}$ \\
\hline 1.18 & 31.167 & 63.284 & 32.118 & 0.697 & $0.018 \pm 0.00068$ \\
\hline 4.20 & 37.051 & 122.592 & 85.540 & 3.000 & $0.076 \pm 0.0023$ \\
\hline 8.48 & 40.158 & 177.220 & 137.062 & 5.618 & $0.143 \pm 0.0041$ \\
\hline $\begin{array}{c}29.30 \\
\left(30 \mathrm{MW}_{\text {th }}\right)\end{array}$ & & & & 19.411 & 0.494 \\
\hline
\end{tabular}


Fig. 6. Nuclear heating rate measurement at the three different reactor power.

TABLE 3

Calculation Results Of The Nuclear Heating Rate At Hanaro.

\begin{tabular}{|c|c|c|c|}
\hline \multicolumn{3}{|c|}{ Contributions } & $\begin{array}{c}\text { Calculated } \\
\text { heating rate per } \\
\text { sample unit mass } \\
{[\mathrm{W} / \mathrm{g}]}\end{array}$ \\
\hline \multirow{6}{*}{ Reactor core } & \multicolumn{2}{|r|}{ Neutrons } & 0.006 \\
\hline & \multirow{5}{*}{$\begin{array}{c}\text { Gamma- } \\
\text { rays }\end{array}$} & Prompt, heavy water & 0.033 \\
\hline & & Prompt, Al sample & 0.059 \\
\hline & & Prompt, etc.* & 0.215 \\
\hline & & Delayed, fission fragment & 0.050 \\
\hline & & Sub-total & 0.357 \\
\hline \multirow{2}{*}{$\begin{array}{l}\text { Al sample } \\
\text { activation }\end{array}$} & \multicolumn{2}{|r|}{ Beta particles } & 0.132 \\
\hline & \multicolumn{2}{|c|}{ Delayed gamma-rays } & 0.013 \\
\hline \multicolumn{3}{|c|}{ Total } & 0.508 \\
\hline
\end{tabular}

Table 3 shows the calculation results of nuclear heating rate equivalent to the nominal reactor power of $30 \mathrm{MW}$. As shown in the Table, it is confirmed that the contributions of the beta particle from aluminum sample activation is pretty big. The contribution of decay gamma-rays from activation of other structure materials such as coolant flow tube is negligible. The calculated heating rate is pretty close to the measured value.

\section{CONCLUSION}

The nuclear heating rate at $\mathrm{CN}$ vertical hole of HANARO was confirmed by measurement and calculation. The simple heat-flow calorimetric method was applied to the calorimeter design. The calculation model for the whole facility including the reactor core and the reflector tank were developed. The calculation methodology has been established to take into account various factors to contribute the nuclear heating. The measured heating rate was reasonably well supported by the calculation. It will be very useful for the cold neutron source installation of a research reactor..

\section{REFERENCES}

[1] A. W. Boyd, "Dosimetry Methods for Structural Materials: Nuclear Heating", AECL-5788, Reprinted from Proceedings of the First ASTM-EURATOM Symposium on Reactor Dosimetry, Petten, Holland, Sept. 22-26, 1975.

[2] F. H. Attix, "Introduction to Radiological Physics and Radiation Dosimetry", New York, John Wiley \& Sons, 1986, p. 427.

[3] International Atomic Energy Agency, "Determination of Absorbed Dose in Reactors", Technical Reports Series No.127, Vienna, 1971, p.123.

[4] T. Kawai, private communications.

[5] R. Dehn. "Measurement of Gamma Heating in D.F.R.", Nucl. Instr. and Meth., Vol.36, p.141, 1965.

[6] M. J. Todd, J. Bishop and D. K. Cartwright, "A Calorimeter for Graphite Dose Rate in Advanced Gas-cooled Reactors", J. Sci. Instrum, Vol.42, p.576, 1965. 